\title{
OPEN A prospective observational prevalence study of elevated HbAlc among elective surgical patients
}

\author{
L. M. Teo ${ }^{1,3 凶}$, W.Y. Lim ${ }^{1}$, Y. Ke ${ }^{2}$, I. K. L. Sia ${ }^{4}$, C. H. Gui ${ }^{4}$ \& H. R. Abdullah ${ }^{1,3 凶}$
}

Type 2 Diabetes Mellitus (DM) is a chronic disease with high prevalence worldwide. Using glycated haemoglobin (HbA1c) as a surrogate for potential pre-DM and DM conditions, our primary objective was to determine the HbA1c epidemiology in non-cardiac elective surgical patients in Singapore. Our secondary aim was to identify risk factors associated with elevated $\mathrm{HbA1c}$. We conducted a prospective, observational single-centre study in adult patients. HbAlc screening was performed. Patient demographics and comorbidities were recorded. Patients were divided into those with $\mathrm{HbA} 1 \mathrm{C} \leq 6.0 \%$ and $\mathrm{HbA} 1 \mathrm{C} \geq 6.1 \%$. Regression analyses were performed to identify associated factors. Subgroup analysis was performed comparing patients with $\mathrm{HbA} 1 \mathrm{C} \geq 6.1 \%$ and $\mathrm{HbA1C} \geq 8.0 \%$. Of the 875 patients recruited, $182(20.8 \%)$ had $\mathrm{HbAlc} \geq 6.1 \%$, of which $32(3.7 \%)$ had $\mathrm{HbA1c} \geq 8 \%$. $\mathrm{HbA1C} \geq 6.1 \%$ was associated with Indian ethnicity [1.07 (1.01-1.13), $\mathrm{p}=0.023], \mathrm{BMI}>27.5[1.07$ (1.02-1.11), $\mathrm{p}=0.002]$, higher preoperative random serum glucose [1.03 (1.02-1.04), $\mathrm{p}<0.001]$, preexisting diagnosis of $D M[1.85(1.75-1.96), \mathrm{p}<0.001]$ and prediabetes [1.44 (1.24-1.67), $\mathrm{p}<0.001]$, and peripheral vascular disease $[1.30(1.10-1.54), \mathrm{p}=0.002]$. $\mathrm{HbA1} \mathrm{c} \geq 8 \%$ had an additional association with age $>60$ years [0.96 $(0.93-0.99), p=0.017]$. The prevalence of elevated $\mathrm{HbA1c}$ is high among the surgical population. Targeted preoperative $\mathrm{HbAlc}$ screening for at-risk elective surgical patients reduces cost, allowing focused use of healthcare resources.

Type 2 Diabetes Mellitus (DM) is a chronic disease with high prevalence worldwide. The International Diabetes Federation (IDF) estimates that today, 463 million people (9.3\% of adults between 20 and 79 years old) worldwide have diabetes. By 2045, this number is predicted to reach 700 million ${ }^{1}$. DM imposes a huge health burden on society. The World Health Organization $(\mathrm{WHO})^{2}$ estimated that 1.6 million deaths were directly attributable to DM in 2016. In addition to increasing the risk of vascular diseases ${ }^{3}$ by two-fold, DM is a major cause of limb amputations $s^{4}$, blindness ${ }^{5}$ and renal failure ${ }^{6}$. This indirectly translates to a high economic burden due to hospitalisations, Emergency Department visits, outpatient physician visits, medications, laboratory tests and allied health services ${ }^{7}$. According to the IDF's estimation, the annual global health expenditure on DM is USD \$760 billion and is expected to grow with increasing prevalence of the disease.

One of the strategies for battling this epidemic is early screening and detection of DM. In addition to fasting blood glucose (FBG), the $\mathrm{WHO}^{8}$ and the American Diabetes Association (ADA) ${ }^{9}$ recommend that glycated haemoglobin (HbA1c) be used as a diagnostic test, with a cut off value of $6.5 \%$ for the diagnosis of DM and $6.1 \%$ for the diagnosis of prediabetes. Since March 2019, HbAlc has been endorsed by the Ministry of Health, Singapore, as an alternative screening test for $\mathrm{DM}^{10}$. The perioperative period presents a good opportunity to screen the adult surgical population for DM. These patients are a "captive audience" who have chosen to present themselves to a healthcare facility. Furthermore, blood investigations are routinely performed pre-operatively and opportunistic DM screening can be performed. Globally, HbA1c screening for DM in elective surgical patients has been initiated since $2013^{11-14}$.

\footnotetext{
${ }^{1}$ Division of Anaesthesiology and Perioperative Medicine, Sengkang General Hospital, Singapore General Hospital, Outram Road, Singapore 169608, Singapore. ${ }^{2}$ Singhealth Anaesthesiology Residency Program, Division of Anaesthesiology and Perioperative Medicine, Singapore General Hospital, Outram Road, Singapore 169608, Singapore. ${ }^{3}$ Duke-NUS (National University of Singapore) Medical School, 8 College Rd, Singapore 169857, Singapore. "National University of Singapore, Yong Loo Lin School of Medicine, 1E Kent Ridge Road, Singapore 119228, Singapore. ${ }^{凶}$ email: teo.li.ming@singhealth.com.sg; hairil.rizal.abdullah@singhealth.com.sg
} 
The perioperative period also provides an opportunity to identify patients with prediabetes and newly diagnosed DM, with appropriate counselling and initiation of treatment of patients with newly diagnosed prediabetes and DM. For known diabetics, this period constitutes a checkpoint for the control of the chronic condition. DMassociated complications (e.g. microvascular and macrovascular) may also affect surgical outcomes ${ }^{9,15}$ adversely. Poorly controlled DM, represented by elevated HbA1C, further exacerbates this as persistent hyperglycemia is a risk factor for endothelial dysfunction, post-operative sepsis, impaired wound healing and mortality ${ }^{16-18}$. Every $1 \%$ in $\mathrm{HbA1c}$ was associated with an increased likelihood of intensive care unit admission, hospital length of stay and greater risk of major complications ${ }^{11}$. As preoperative HbA1C has a significant impact on short- and long- term health outcomes, the perioperative period facilitates patient education and raises awareness. The importance of good glycaemic control should be emphasized to patients (both known and newly diagnosed) and optimization should be undertaken prior to surgery.

Currently, the epidemiology of elevated $\mathrm{HbA1C}$ levels among patients presenting for non-cardiac elective surgery in Singapore is not known. Using preoperative HbAlc and the established cut-off values ${ }^{8,9}$, our primary objective was to determine the proportion of patients with $\mathrm{HbAlc} \geq 6.1 \%$ in elective, non-cardiac surgical patients in Singapore. Our secondary aim was to identify risk factors associated with $\mathrm{HbAlc} \geq 6.1 \%$ and $\mathrm{HbA} 1 \mathrm{C} \geq 8.0 \%$.

\section{Methodology}

Ethics approval. Ethics approval for the study was obtained from Singhealth's Centralised Institutional Review Board (CIRB, Reference Number 2018/3225). This study is registered with the clinicaltrials.gov database (NCT04070963). The study protocol was performed in accordance to the Declaration of Helsinki.

Study design. We conducted a prospective, observational single-centre study at the Preoperative Assessment Centre (PAC) of Singapore General Hospital (SGH) from May 2019 to Aug 2019. SGH is a 1700 bedded government-aided tertiary academic referral center that performs approximately 30,000 elective surgical procedures per annum. The inclusion criteria were: (1) adult patients aged 21 and above, and (2) non-cardiac elective operations who required preoperative blood investigations. We excluded patients who were unable to provide consent, or in situations where there was inadequate blood sample to perform the HbAlc test. Participants were approached and included in our study after written informed consent was obtained. Consent forms were in English, and participants from non-English speaking backgrounds were provided with a translator.

Patients' demographic information including age, gender, ethnicity, and BMI were collected. The functional status, including METs and ASA status were recorded. Medical comorbidities including smoking history, DM, hypertension, dyslipidaemia, history of stroke, AMI or ischaemic heart disease, COPD were also recorded. Potential confounders, such as the presence of haemoglobinopathies e.g. thalassaemia were sought. These were sourced from our institution's clinical information system [Sunrise Clinical Manager (SCM), Allscripts, Illinois, USA] and stored in our enterprise data repository and analytics system (SingHealth-IHiS Electronic Health Intelligence System), which integrates information from multiple healthcare systems including administrative, clinical and ancillary healthcare systems. Medication history, in particular, the treatment of DM e.g. OHGA and insulin were reviewed. Surgical details such as the type of surgery and the associated surgical disciplines were also recorded.

$\mathrm{HbAlc}$ test was added to routine preoperative blood investigations for all participants. HbA1c measurement was carried out by immunoassay with the Roche Cobas c501 analyzer (Roche Diagnostics). Our method is accredited by the National Glycoprotein Standardization Program (NGSP) and standardized to the Diabetes Control and Complications Trial (DCCT) assay. We sought to determine the prevalence of elevated HbA1c (>6.0\%), with further stratification at the levels of HbA1c $\geq 8.0 \%$ among elective, non-cardiac surgical patients. This stratification is based on levels previously described in the literature ${ }^{8,9,19}$.

Sample size estimation. Using a precision of $2 \%$ and published inpatient DM prevalence of $10 \%{ }^{20}$ and $95 \%$ confidence interval ( $8-12 \%$ prevalence limit), the estimated sample size required was 865 . A total of 888 patients were recruited, taking into consideration potential dropouts due to laboratory errors or insufficient blood samples for HbAlc testing.

Statistical analysis. Patient demographics and clinical characteristics between the groups where $\mathrm{HbA} 1 \mathrm{C}$ is $\geq 6.1 \%$ and $\leq 6.0 \%$ were compared (Table 1 ). HbAlc value of $\geq 6.1 \%$ was chosen based on local literature ${ }^{21}$. This group of patients is at risk of perioperative hyperglycaemia and poorer surgical outcomes ${ }^{22,23}$. For continuous variables, Kruskal-Wallis test was used for non-parametric variables and ANOVA was used for variables with normal distribution. For categorical variables, the chi-squared test was used to compare the proportions between the groups. Subgroup analysis for $\mathrm{HbA} 1 \mathrm{C} \geq 8.0 \%$ was done (Table 2).

Multivariable logistic regression was performed to determine the independent predictors for $\mathrm{HbA} 1 \mathrm{C} \geq 6.1 \%$. Variables with known clinical probability for contributing to elevated HbA1c such as demographics and preoperative clinical risk factors, as well as covariables with significance levels of $\mathrm{p}<0.1$ in the univariate analysis were also included in the multivariable model. The effect size was reported as an odds ratio (OR) and its $95 \%$ confidence interval (CI). To avoid multicollinearity, Variance Inflation Factor (VIF) was used to ensure all factors in the regression models do not exceed $5.0^{24}$.

Preoperative serum glucose was further assessed for its correlation and prediction of preoperative HbA1C value. Correlation between haemoglobin level and HbAlc was investigated via Pearson correlation coefficient. All analyses, statistical computing and visualisation were carried out in the R environment version 1.2.1335 using "ggplot2" R library package ${ }^{25}$. 


\begin{tabular}{|c|c|c|c|c|c|}
\hline & $\mathrm{HbA1C} \leq 6.0 \%(\mathrm{~N}=693)$ & HbAIC $\geq 6.1 \%(N=182)$ & Total $(\mathrm{N}=\mathbf{8 7 5})$ & p value & Missing \\
\hline Age & $49.6(16.4)$ & $61.6(11.9)$ & $52.1(16.3)$ & $<0.001$ & \\
\hline Gender (female) & $346(49.9)$ & $74(40.7)$ & $420(48.0)$ & 0.026 & \\
\hline \multicolumn{6}{|l|}{ Ethnicity } \\
\hline Chinese & 497 (71.7) & $116(63.7 \%)$ & $613(70.1)$ & \multirow{4}{*}{0.002} & \\
\hline Malay & $75(10.8)$ & $23(12.6 \%)$ & $98(11.2)$ & & \\
\hline Indian & $68(9.8)$ & $35(19.2 \%)$ & $103(11.8)$ & & \\
\hline Others & $53(7.6)$ & $8(4.4 \%)$ & $61(7.0)$ & & \\
\hline BMI & $25.4(5.2)$ & $28.8(5.9)$ & $26.1(5.5)$ & $<0.001$ & \\
\hline ASA 1 & $159(22.9)$ & $3(1.6)$ & $162(18.5)$ & \multirow{3}{*}{$<0.001$} & \\
\hline ASA 2 & $461(66.5)$ & $120(65.9)$ & $581(66.4)$ & & \\
\hline ASA 3 and 4 & $73(10.5)$ & $59(32.4)$ & $132(15.1)$ & & \\
\hline \multicolumn{6}{|l|}{ Best known function } \\
\hline METs $<4$ & $10(1.5)$ & $14(8.4)$ & $24(2.9)$ & \multirow{3}{*}{$<0.001$} & \multirow{3}{*}{53} \\
\hline METs $4-10$ & $177(27.0)$ & $43(25.9)$ & $220(26.8)$ & & \\
\hline METs $>10$ & $469(71.5)$ & $109(65.7)$ & $578(70.3)$ & & \\
\hline \multicolumn{6}{|l|}{ Admission type } \\
\hline Inpatient & $503(72.8)$ & $142(78.5)$ & $645(74.0)$ & 0.122 & 3 \\
\hline Day surgery & $188(27.2)$ & $39(21.5)$ & $227(26.0)$ & & \\
\hline Hemoglobin $\left(\mathrm{g} \mathrm{dL}^{-1}\right)$ & $13.7(1.6)$ & $13.4(1.6)$ & $13.6(1.6)$ & 0.006 & \\
\hline $\begin{array}{l}\text { Preoperative Random Serum Glucose } \\
\left(\mathrm{mmol} \mathrm{L}^{-1}\right)\end{array}$ & $5.5(1.2)$ & $8.4(3.3)$ & $6.1(2.2)$ & $<0.001$ & \\
\hline Creatinine $\left(\mu \mathrm{mol} \mathrm{L}^{-1}\right)$ & $76.2(71.4)$ & $106.1(122.3)$ & $82.4(85.3)$ & $<0.001$ & \\
\hline HbA1C value (\%) & $5.4(0.4)$ & $7.2(1.2)$ & $5.74(0.97)$ & $<0.001$ & \\
\hline Smoker & $66(9.5)$ & $14(7.7)$ & $80(9.1)$ & 0.743 & \\
\hline \multicolumn{6}{|l|}{ Nature of operation } \\
\hline General Surgery & $194(28.0)$ & $45(24.7)$ & $239(27.3)$ & 0.378 & \\
\hline Urology & $85(12.3)$ & $35(19.2)$ & $120(13.7)$ & 0.015 & \\
\hline Gynecology & $74(10.7)$ & $9(4.9)$ & $83(9.5)$ & 0.019 & \\
\hline Vascular & $18(2.6)$ & $20(11.0)$ & $38(4.3)$ & $<0.001$ & \\
\hline Orthopaedics & $233(33.6)$ & $58(31.9)$ & $291(33.3)$ & 0.655 & \\
\hline Subspecialty surgeries & $110(15.9)$ & $20(11.0)$ & $130(14.9)$ & 0.099 & \\
\hline \multicolumn{6}{|l|}{ Past medical history } \\
\hline Preexisting diabetes mellitus & $31(4.5)$ & $136(74.7)$ & $167(19.1)$ & $<0.001$ & \\
\hline Pre-diabetes & $6(0.9)$ & $9(4.9)$ & $15(1.7)$ & $<0.001$ & \\
\hline Hypertension & $167(24.1)$ & $128(70.3)$ & $295(33.7)$ & $<0.001$ & \\
\hline Previous stroke & $11(1.6 \%)$ & $18(9.9 \%)$ & $29(3.3 \%)$ & $<0.001$ & \\
\hline Previous AMI & $17(2.5 \%)$ & $26(14.3 \%)$ & $43(4.9 \%)$ & $<0.001$ & \\
\hline Peripheral vascular disease & $1(0.1 \%)$ & $12(6.6 \%)$ & $13(1.5 \%)$ & $<0.001$ & \\
\hline COPD & $4(0.6 \%)$ & $4(2.2 \%)$ & $8(0.9 \%)$ & 0.041 & \\
\hline
\end{tabular}

Table 1. Patient demographics stratified by HbA1C cut-off of $6.0 \%$. Values are mean (SD) or number (proportions). Mann Whitney U test for continuous variable and Chi Square Test-for discrete variable. Mean or count ( \pm SD or \%). BMI Body Mass Index, $A S A$ American society of Anaesthesiologists physical status classification, MET metabolic equivalents, OHGA Oral Hypoglycemic agents, AMI Acute myocardial infarction, $C O P D$ Chronic obstructive pulmonary disease, $A C E$ Angiotensin-Converting Enzyme, $A R B$ Angiotensin II receptor blocker.

\section{Results}

A total of 888 patients were recruited from 9 May 2019 to 27 Aug 2019 in the preoperative assessment centre (PAC) of a tertiary hospital in Singapore. Of those, 13 were excluded as they had a history of thalassemia. Our final analysis was carried out with 875 patient observations.

Stratifying patients based on $\mathrm{HbAlc}, 693$ (79.2\%) had $\mathrm{HbAlC} \leq 6.0 \%$ and $182(20.8 \%)$ patients who had $\mathrm{HbAlc} \geq 6.1 \%$. The mean age was 49.6 in the $\mathrm{HbA} 1 \mathrm{C} \leq 6.0 \%$ group and 61.6 in the $\mathrm{HbA} 1 \mathrm{C} \geq 6.1 \%$ group. The prevalence of pre-existing diabetes was 31 (3.5\%) in the HbA1C $\leq 6.0 \%$ group and $136(15.5 \%)$ in the $\mathrm{HbA} 1 \mathrm{C} \geq 6.1 \%$ group. Of note, 37 (4.2\%) patients who did not have a diagnosis of DM or Pre-DM had HbA1C of $\geq 6.1 \%$. The $\mathrm{HbA} 1 \mathrm{C} \geq 6.1 \%$ group also had more males, more likely to be Indian ethnicity, metabolic equivalents $(\mathrm{METs})<4$, higher American Society of Anaesthesiologist (ASA) status, higher body mass index (BMI), higher preoperative random serum glucose and creatinine levels and higher incidence of chronic diseases such as hypertension, previous stroke or acute myocardial infarction (AMI), chronic obstructive pulmonary disease 


\begin{tabular}{|c|c|c|c|c|c|c|}
\hline & \multicolumn{3}{|c|}{ HbA1C $\geq 6.1 \%$} & \multicolumn{3}{|c|}{ HbA1C $\geq 8.0 \%$} \\
\hline & \multirow{2}{*}{\begin{tabular}{|l} 
Univariable \\
p value
\end{tabular}} & \multicolumn{2}{|c|}{ Multivariable } & \multirow{2}{*}{$\begin{array}{l}\text { Univariable } \\
\text { p value }\end{array}$} & \multicolumn{2}{|c|}{ Multivariable } \\
\hline & & p value & OR $(95 \% \mathrm{Cl})$ & & p value & OR $(95 \% \mathrm{Cl})$ \\
\hline \multicolumn{7}{|l|}{ Age } \\
\hline$<40$ & Reference & 0.723 & $1.01(0.96-1.06)$ & Reference & 0.965 & $1.00(0.97-1.03)$ \\
\hline $40-60$ & $<0.001$ & 0.370 & $1.03(0.97-1.09)$ & 0.068 & 0.017 & $0.96(0.93-0.99)$ \\
\hline$>60$ & $<0.001$ & & & 0.339 & & \\
\hline Gender (female) & 0.0259 & 0.557 & $0.99(0.95-1.03)$ & 0.492 & & \\
\hline \multicolumn{7}{|l|}{ Race } \\
\hline Chinese & Reference & 0.863 & $1.01(0.95-1.07)$ & Reference & 0.308 & $1.00(0.98-1.06)$ \\
\hline Malay & 0.300 & 0.023 & $1.07(1.01-1.13)$ & 0.054 & 0.003 & $1.10(1.02-1.09)$ \\
\hline Indian & $<0.001$ & 0.290 & $0.96(0.90-1.03)$ & $<0.001$ & 0.585 & $0.99(0.95-1.03)$ \\
\hline Others & 0.284 & & & 0.353 & & \\
\hline BMI 18.5-27.5 & Reference & & & Reference & & \\
\hline $\mathrm{BMI}<18.5$ & 0.043 & 0.378 & $0.96(0.87-1.05)$ & 0.569 & 0.884 & $1.00(0.95-1.07)$ \\
\hline $\mathrm{BMI}>27.5$ & $<0.001$ & 0.002 & $1.07(1.02-1.11)$ & $<0.001$ & 0.222 & $1.02(0.99-1.04)$ \\
\hline ASA 1 & Reference & & & Reference & & \\
\hline ASA 2 & $<0.001$ & 0.778 & $1.01(0.96-1.06)$ & 0.057 & 0.616 & $1.01(0.98-1.04)$ \\
\hline ASA 3 and 4 & $<0.001$ & 0.749 & $1.01(0.94-1.09)$ & $<0.001$ & 0.725 & $1.01(0.97-1.05)$ \\
\hline MET 1-4 & Reference & & & Reference & & \\
\hline MET 4-10 & $<0.001$ & 0.129 & $1.10(0.97-1.24)$ & 0.151 & & \\
\hline MET $>10$ & $<0.001$ & 0.733 & $1.02(0.91-1.14)$ & 0.198 & & \\
\hline \multicolumn{7}{|l|}{ Hemoglobin (g/dL) } \\
\hline$>13$ & Reference & 0.599 & $1.01(0.97-1.06)$ & Reference & 0.428 & $1.01(0.99-1.04)$ \\
\hline $11-13$ & 0.009 & 0.130 & $0.93(0.85-1.02)$ & 0.031 & 0.002 & $0.92(0.88-0.97)$ \\
\hline$<11$ & 0.590 & & & 0.339 & & \\
\hline Preoperative random serum glucose $(\mathrm{mmol} / \mathrm{L})$ & $<0.001$ & $<0.001$ & $1.03(1.02-1.04)$ & $<0.001$ & $<0.001$ & $1.03(1.02-1.04)$ \\
\hline Creatinine & $<0.001$ & 0.860 & $1.00(1.00-1.00)$ & 0.393 & & \\
\hline Diabetes mellitus & $<0.001$ & $<0.001$ & $1.85(1.75-1.96)$ & $<0.001$ & $<0.001$ & $1.09(1.05-1.13)$ \\
\hline Prediabetes & $<0.001$ & $<0.001$ & $1.44(1.24-1.67)$ & 0.455 & & \\
\hline Hypertension & $<0.001$ & 0.094 & $1.04(0.99-1.09)$ & $<0.001$ & 0.069 & $0.97(0.95-1.00)$ \\
\hline Previous stroke & $<0.001$ & 0.553 & $0.97(0.87-1.08)$ & $<0.001$ & 0.150 & $1.05(0.99-1.12)$ \\
\hline Previous AMI & $<0.001$ & 0.301 & $1.05(0.96-1.15)$ & $<0.001$ & 0.315 & $1.03(0.98-1.09)$ \\
\hline Peripheral vascular disease & $<0.001$ & 0.002 & $1.30(1.10-1.54)$ & $<0.001$ & 0.016 & $1.13(1.03-1.24)$ \\
\hline COPD & 0.041 & 0.422 & $0.92(0.76-1.12)$ & 0.169 & & \\
\hline
\end{tabular}

Table 2. Univariable and Multivariable analysis of those significant for $\mathrm{HbA} 1 \mathrm{C} \geq 6.1 \%$. BMI Body Mass Index, ASA American society of Anesthesiologists physical status classification, MET metabolic equivalents, $A M I$ Acute myocardial infarction, COPD Chronic obstructive pulmonary disease.

(COPD) and peripheral vascular disease (Table 1). Figure 1 shows the relationship between HbA1C and preoperative glucose levels as stratified by the presence or absence of known DM.

Based on electronic medical records, 167 (19.1\%) of the patients are known diabetics and $15(1.7 \%)$ had a pre-existing diagnosis of prediabetes. Amongst the 693 (79.2\%) patients who were not known to have DM, 5 patients had $\mathrm{HbAlc} \geq 6.5 \%$, resulting in a prevalence of undiagnosed DM of $0.5 \%$. There were $32(3.7 \%)$ patients who were not known to have prediabetes.

Adjusted regression analysis showed that $\mathrm{HbA1C}$ of $\geq 6.1 \%$ was associated with Indian ethnicity [1.07 (1.01-1.13), $\mathrm{p}=0.023$ ] [(OR(95\%Cl), $\mathrm{p}$ value)], BMI more than 27.5 [1.07 (1.02-1.11), $\mathrm{p}=0.002]$, higher preoperative random serum glucose $(\mathrm{mmol} / \mathrm{L})[1.03(1.02-1.04), \mathrm{p}<0.001]$, pre-existing diagnosis of DM [1.85 $(1.75-1.96), \mathrm{p}<0.001]$ and prediabetes [1.44 (1.24-1.67), $\mathrm{p}<0.001]$, and diagnosis of peripheral vascular disease [1.30 (1.10-1.54), $\mathrm{p}=0.002]$. The adjusted analysis did not detect significance in age, ASA status, MET functional status, preoperative haemoglobin and creatinine levels, and other chronic diseases such as hypertension, COPD and previous stroke and AMI (Table 2).

Subgroup analysis of $\mathrm{HbA} 1 \mathrm{C} \geq 8.0 \%$ was conducted for poorly controlled diabetics. $32 / 875$ (3.7\%) had $\mathrm{HbA} 1 \mathrm{C} \geq 8.0 \%$. Factors that are associated with $\mathrm{HbA} 1 \mathrm{C} \geq 8.0 \%$ include age of $>60$ years old [0.96 (0.93-0.99), $\mathrm{p}=0.017]$, Indian ethnicity [1.10 (1.02-1.09), $\mathrm{p}=0.003]$, higher preoperative random serum glucose level [1.03 (1.02-1.04), $\mathrm{p}<0.001]$, pre-existing diagnosis of DM $(1.09(1.05-1.13), \mathrm{p}<0.001)$, and peripheral vascular disease [1.13 (1.03-1.24), $\mathrm{p}=0.016]$. Interestingly, haemoglobin of $<11.0 \mathrm{~g} / \mathrm{dL}$ was associated with lower incidence of $\mathrm{HbA} 1 \mathrm{C}>8.0 \%$ on the adjusted analysis [0.92 $(0.88-0.97), \mathrm{p}=0.002]$ (Table 2$)$. 


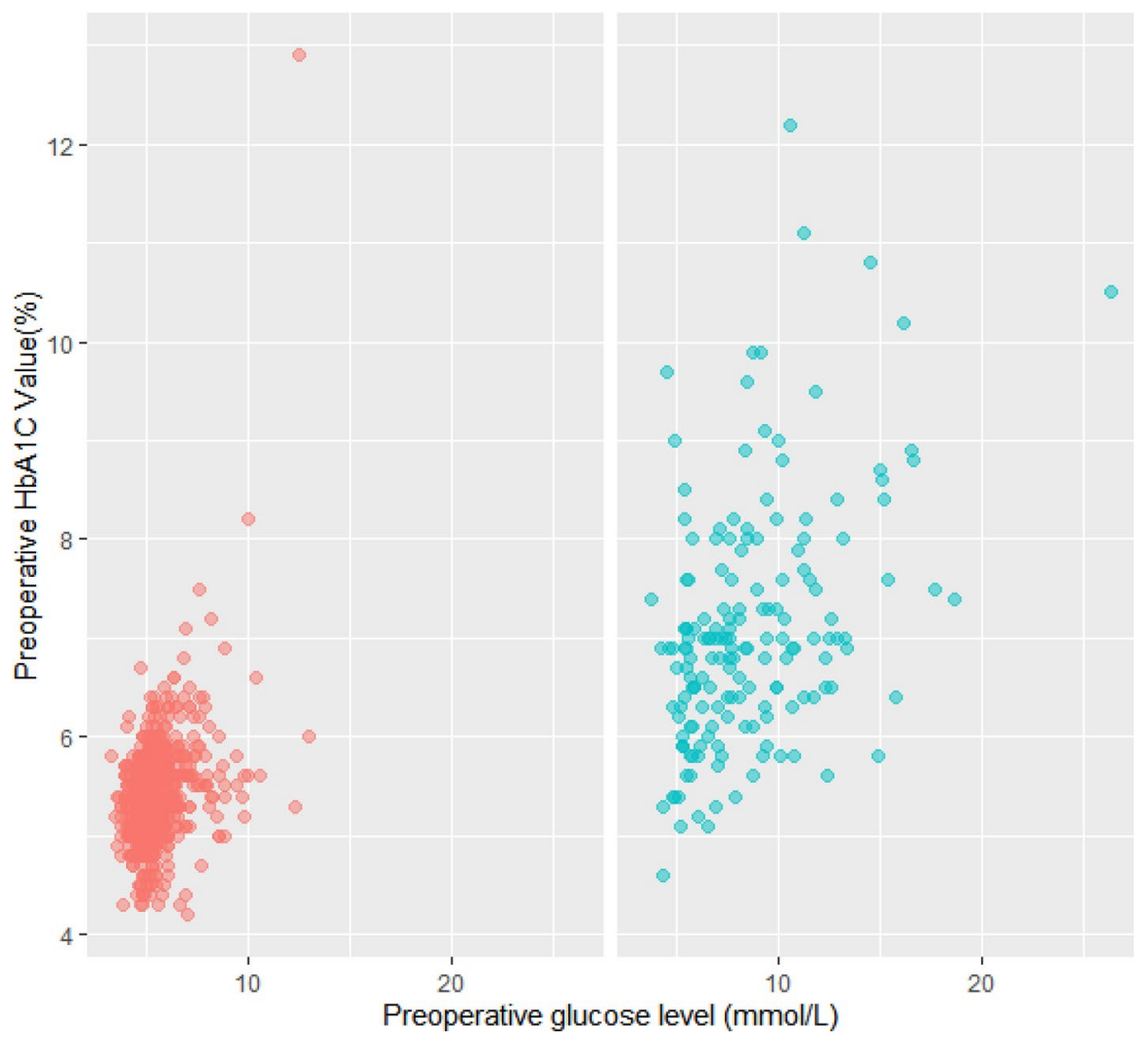

Figure 1. Comparison of preoperative HbAlc and glucose level in patients with DM (blue) and without DM (red). Each dot represents a single patient. HbA1c glycated haemoglobin, DM diabetes mellitus.

\begin{tabular}{|c|c|c|c|c|}
\hline & $\mathrm{HbA1C} \leq 6.0 \%(\mathrm{~N}=31)$ & HbA1C $\geq 6.1 \%(\mathrm{~N}=136)$ & Total $(\mathrm{N}=167)$ & p value \\
\hline \multicolumn{4}{|c|}{ Treatment of diabetes } & $<0.001$ \\
\hline OHGA & $15(48.4 \%)$ & $102(75.0 \%)$ & $117(70.1 \%)$ & \\
\hline Insulin & $2(6.5 \%)$ & $4(2.9 \%)$ & $6(3.6 \%)$ & \\
\hline OHGA+insulin & $0(0.0 \%)$ & $15(11.0 \%)$ & $15(9.0 \%)$ & \\
\hline Diet & $14(45.2 \%)$ & $15(11.0 \%)$ & $29(17.4 \%)$ & \\
\hline
\end{tabular}

Table 3. Medications in those diagnosed with DM. Values are number (proportions). DM diabetes mellitus, $O H G A$ oral hypoglycemic agents.

Within the group of 167 diagnosed diabetics, those who were on insulin with or without oral hypoglycaemic agent (OHGA) account for $12.6 \%$ of the patients. Table 3 shows the distribution of the patients on DM medication and their HbA1c levels. There were 109 (65.2\%) patients on metformin, 54 (32.3\%) patients on sulphonylurea and $31(18.5 \%)$ patients on sodium-glucose cotransporter 2 (SGLT2) inhibitors.

\section{Discussion}

$20.8 \%$ of our study population had $\mathrm{HbAlc} \geq 6.1 \%$. Within this group, 37 (4.2\%) patients did not have a diagnosis of pre-DM or DM, suggesting that we could utilize the perioperative encounter as a screening opportunity. However, in our institution, the cost of HbAlc testing is 2.5 times that of blood glucose testing and routine preoperative HbAlc screening for all patients may not be cost-effective. As such, we recommend a more targeted approach. Based on our analysis of risk factors, HbAlc screening should be considered in patients aged 60 and above, of Indian ethnicity, have a high BMI $>27.5$ or have pre-existing DM, prediabetes or peripheral vascular disease. For patients with HbAlc between 6 and $8 \%$, close monitoring of blood glucose levels four times a day ${ }^{26,27}$ in the postoperative period to achieve blood glucose levels between 6 and $10 \mathrm{mmol} / \mathrm{L}$ is recommended ${ }^{26,28}$.

Diabetes mellitus increases the risk for perioperative complications such as wound infection (OR 2.3 $)^{29}$, acute kidney injury $(\mathrm{OR} 4.15)^{30}$, prolonged hospitalization (OR 1.60$)^{30}$ and even mortality (OR 1.51$)^{31}$. Every $1 \%$ in $\mathrm{HbA1c}$ is also associated with an increased likelihood of ICU admission, hospital LOS and greater risk of 
major complications ${ }^{11}$. Elective surgery should be deferred, if possible, in patients with $\mathrm{HbA1c} \geq 8.0 \%$, to allow optimization of glycaemic control. In addition to the short term increased perioperative risks in diabetics, DM is an unrelenting disease with long term sequelae if poorly controlled. High baseline HbAlc value $(7.8 \% \pm 1)$ is associated with diabetes progression over 3 years ${ }^{32}$. Disease progression was defined as advancing to sustained insulin use or $\mathrm{HbAlc}>8.5 \%$ when treated with two or more OHGAs. For patients with prediabetes, there is also a $5-10 \%$ annualized conversion rate to DM, with complications like nephropathy and retinopathy already beginning to develop in the prediabetes state ${ }^{33}$. Conversely, in patients with $\mathrm{HbA} 1 \mathrm{c}<6 \%$, the risk of long term complications is reduced ${ }^{34}$. The perioperative period presents a screening opportunity for prediabetes, DM and other chronic medical conditions (e.g.hypertension). For patients with existing conditions, it allows assessment and optimization of those chronic conditions, forming an effective "teachable moment" 35 . Appropriate referrals to other healthcare providers and a multidisciplinary approach would lead to improved long-term outcomes and public health.

In our study, Indian ethnicity was associated with elevated HbA1c levels and poorly controlled DM. In the USA and Europe, even at low BMI, a higher incidence of type 2 DM was reported in Indians compared to other ethnic groups ${ }^{36,37}$. In Singapore, the prevalence of DM in the Indian population was twice as high compared to the Chinese population $(20-26 \% \text { versus } 10-13 \%)^{38}$. Possible hypotheses for increased DM susceptibility in Indian ethnicity include reduced beta cell function, impaired insulin activity due to low lean mass and ectopic fat deposition on the liver and muscles ${ }^{39}$. There are limited dietary, exercise and behavioural studies conducted among Indian ethnicity and future research into potential clinical and public health interventions to address these susceptibilities are needed.

From the review of medical records, the prevalence of DM in our study population is $19 \%$, higher than the general adult Singapore population $(14.2 \%)^{40}$. However, this is not unexpected due to the increasing prevalence of DM with age. The mean (SD) age of our study population was 52.1 (16.3) years. Our results are consistent with existing literature on non-cardiac surgical populations which showed similar DM prevalence rates and an older patient population ${ }^{12,13,41,42}$. In the study by Yong et al. ${ }^{11}$ where the participants were aged 55 and above, the prevalence of DM in their population was higher at 30\%. Diabetes-related comorbidities may also necessitate surgical intervention, further accounting for the increased prevalence amongst the surgical population.

Undiagnosed diabetics have a three-fold increased risk in 1-year mortality compared to non-diabetics ${ }^{43}$. Early diagnosis, intervention and effective surveillance may reduce the socioeconomic burden on the healthcare system. In our study, the prevalence of undiagnosed DM was surprisingly low at $0.5 \%$. This is markedly reduced from $7.4 \%$ reported in an earlier study in $2016^{43}$. In other international studies, the prevalence ranged from 1.6 to $34 \%^{12,14,21,41}$. Shohat et al. reported a prevalence of $40 \%$ in 1461 patients who underwent joint arthroplasty surgery ${ }^{12}$. We postulate that the local take-up rate of the Singaporean government heavily subsidised community diabetes screening programme by 6-7 in every 10 adults aged 40 and above ${ }^{44}$ has contributed to the significant improvement and low rate of undiagnosed DM in our surgical population.

Prior to the recommendation of HbAlc for the diagnosis of DM, fasting blood glucose (FBG) and oral glucose tolerance test (OGTT) had been the established investigations. In the perioperative clinic setting, FBG and OGTT are challenging to perform due to requirements for fasting. The advantages of performing HbAlc testing compared to FBG levels and OGTT include convenience for patients (fasting is not required), pre-analytical stability of the sample and reduced day-to-day variation as a result of stress or illness, reflecting average plasma glucose levels over the previous 8-12 weeks ${ }^{45}$. However, potential drawbacks include HbA1c variability due to the presence of haemoglobin variants (e.g. thalassaemia), ethnicity and conditions that affect red cell turnover (eg. haemodialysis and glucose-6-phosphate-dehydrogenase deficiency) ${ }^{46}$. In view of these limitations, Lim et al. evaluated HbA1c (versus FBG or OGTT) as a diabetes screening modality in a multi-ethnic Singapore population, and demonstrated that $\mathrm{HbAlc}$ is an appropriate alternative to $\mathrm{FBG}^{21}$. Despite this, we excluded patients with haemoglobinopathies from our analysis as HbA1c assay techniques may be significantly affected by blood samples containing haemoglobin variants ${ }^{47}$.

Conditions that influence erythrocyte turnover may affect HbAlc levels. Anaemia may: (1) increase erythrocyte turnover, lowering HbAlc levels, or (2) reduce turnover or modify configuration of haemoglobin (Hb), and increasing the glycation of its $\mathrm{N}$-terminal valine, leading to higher HbAlc values ${ }^{48}$. Currently, there is no consensus as to the effect of anaemia on $\mathrm{HbA} 1 \mathrm{c}^{49,50}$. Nevertheless, care should be taken while interpreting the results. In our data, we observed no difference in haemoglobin levels in the two groups stratified by HbA1c greater or lower than $6 \%$ (Table 1 ).

This study has several limitations. Firstly, familial history of DM was not elicited in our preoperative assessment. A positive family history of $\mathrm{DM}^{51,52}$, especially in first degree relatives, is a strong independent predictor for developing DM, even after accounting for other risk factors (e.g. physical activity, waist circumference and $\mathrm{BMI})^{53}$. Familial history of DM should be considered when conducting targeted preoperative HbA1c screening of surgical patients. Secondly, patients undergoing cardiac surgery (where higher DM prevalence may be present ${ }^{54}$ ) were excluded and therefore our findings may not accurately reflect the HbAlc distribution among the surgical population. A larger multi-centre study, including all surgical disciplines is required to determine the actual prevalence of DM in the surgical population and to validate a HbA1c screening protocol among elective surgical patients in our local population. Thirdly, this being a prevalence study, it is not sufficiently powered to detect surgical and post-operative complications.

\section{Conclusion}

The prevalence of patients with $\mathrm{HbA} 1 \mathrm{c} \geq 6.1 \%$ in our study population was $20.8 \%$. Preoperative HbA1C screening identified $4.2 \%$ of patients who did not have a previous diagnosis of DM or prediabetes, suggesting that we could utilize the perioperative encounter as a screening opportunity. Targeted preoperative HbA1 screening for 
at risk elective surgical patients may be more cost-effective and allows focused use of healthcare resources. In line with the ADA recommendations, risk assessment and $\mathrm{HbAlc}$ screening should be considered in asymptomatic individuals and if normal, repeated testing at 3 yearly intervals is reasonable.

Received: 14 July 2020; Accepted: 23 October 2020

Published online: 04 November 2020

\section{References}

1. International Diabetes Federation Diabetes Atlas 9th edition 2019. https://www.diabetesatlas.org. Accessed 08 Aug 2020.

2. World Health Organization. Diabetes. https://www.who.int/news-room/fact-sheets/detail/diabetes. Accessed 08 Aug 2020.

3. The Emerging Risk Factors Collaboration. Diabetes mellitus, fasting blood glucose concentration, and risk of vascular disease: A collaborative meta-analysis of 102 prospective studies. Lancet 375, 2215-2222 (2010).

4. Narres, M. et al. Incidence of lower extremity amputations in the diabetic compared with the non-diabetic population: A systematic review. PLoS One 12, e0182081 (2017).

5. Flaxman, S. R. et al. Global causes of blindness and distance vision impairment 1990-2020: A systematic review and meta-analysis. Lancet Glob. Health 5, e1221-e1234 (2017).

6. Saran, R. et al. US renal data system 2015 annual data report: Epidemiology of kidney disease in the United States. Am. J. Kidney Dis. 67(Svii), S1-305 (2016).

7. Ng, C. S., Toh, M. P. H., Ko, Y. \& Lee, J. Y. C. Direct medical cost of type 2 diabetes in Singapore. PLoS One 10, e0122795 (2015).

8. World Health Organization. Use of Glycated Haemoglobin (HbA1c) in Diagnosis of Diabetes Mellitus: Abbreviated Report of a WHO Consultation. https://apps.who.int/iris/bitstream/handle/10665/70523/WHO_NMH_CHP_CPM_11.1_eng.pdf(2011).

9. American Diabetes Association. Diabetes care in the hospital: Standards of medical care in diabetes-2020. Diabetes Care 43, S193-S202 (2020).

10. Ministry of Health, Singapore. Regulations, Guidelines and Circulars. https://www.moh.gov.sg/licensing-and-regulation/regulation s-guidelines-and-circulars/details/release-of-new-screening-test-review-committee-(strc)-guidelines-including-changes-to-diabe tes-mellitus-lipid-disorders-and-cervical-cancer-screening.

11. Yong, P. H. et al. The presence of diabetes and higher HbAlc Are independently associated with adverse outcomes after surgery. Diabetes Care 41, 1172-1179 (2018).

12. Shohat, N. et al. All patients should be screened for diabetes before total joint arthroplasty. J. Arthroplasty 33, 2057-2061 (2018).

13. Koumpan, Y., VanDenKerkhof, E. \& van Vlymen, J. An observational cohort study to assess glycosylated hemoglobin screening for elective surgical patients. Can. J. Anaesth. 61, 407-416 (2014).

14. Feldman-Billard, S., Sedira, N., Boelle, P.-Y., Poisson, F. \& Héron, E. High prevalence of undiagnosed diabetes and high risk for diabetes using HbA1c criteria in middle-aged patients undergoing cataract surgery. Diabetes Metab. 39, 271-275 (2013).

15. Epstein, N. E. Predominantly negative impact of diabetes on spinal surgery: A review and recommendation for better preoperative screening. Surg. Neurol. Int. 8, 107 (2017).

16. Walid, M. S. et al. Prevalence of previously unknown elevation of glycosylated hemoglobin in spine surgery patients and impact on length of stay and total cost. J. Hosp. Med. 5, E10-E14 (2010).

17. O'Sullivan, C. J. et al. Haemoglobin Alc (HbA1C) in non-diabetic and diabetic vascular patients. Is HbA1C an independent risk factor and predictor of adverse outcome?. Eur. J. Vasc. Endovasc. Surg. 32, 188-197 (2006).

18. van den Boom, W. et al. Effect of $\mathrm{A} 1 \mathrm{C}$ and glucose on postoperative mortality in noncardiac and cardiac surgeries. Diabetes Care 41, 782-788 (2018).

19. Mendez, C. E. et al. Preoperative diabetes optimization program. Clin. Diabetes 36, 68-71 (2018).

20. National Diabetes Inpatient Audit (NaDIA), Open data-2013-NHS Digital. NHS Digital https://www.hscic.gov.uk/catalogue/ PUB14358.

21. Lim, W. Y. et al. Screening for diabetes with HbAlc: Test performance of HbAlc compared to fasting plasma glucose among Chinese, Malay and Indian community residents in Singapore. Sci. Rep. 8, 12419 (2018).

22. Noordzij, P. G. et al. Increased preoperative glucose levels are associated with perioperative mortality in patients undergoing noncardiac, nonvascular surgery. Eur. J. Endocrinol. 156, 137-142 (2007).

23. Gustafsson, U. O., Thorell, A., Soop, M., Ljungqvist, O. \& Nygren, J. Haemoglobin A1c as a predictor of postoperative hyperglycaemia and complications after major colorectal surgery. Br. J. Surg. 96, 1358-1364 (2009).

24. Kim, J. H. Multicollinearity and misleading statistical results. Korean J. Anesthesiol. 72, 558-569 (2019).

25. Kassambara, A. Drawing Survival Curves using 'ggplot2' [R package survminer version 0.4.6]. 1 (2019).

26. Moghissi, E. S. et al. American Association of Clinical Endocrinologists and American Diabetes Association consensus statement on inpatient glycemic control. Endocr. Pract. 15, 353-369 (2009).

27. Sigal, R., Armstrong, M., Colby, P. \& Kenny, G. P. Canadian Diabetes Association clinical practice guidelines: Physical activity and diabetes. Can. J. Diabetes 20, 20 (2013).

28. Dhatariya, K. et al. NHS Diabetes guideline for the perioperative management of the adult patient with diabetes. Diabet. Med. 29, 420-433 (2012).

29. Jämsen, E. et al. Obesity, diabetes, and preoperative hyperglycemia as predictors of periprosthetic joint infection: A single-center analysis of 7181 primary hip and knee replacements for osteoarthritis. J. Bone Jt. Surg. Am. 94, e101 (2012).

30. Kubal, C., Srinivasan, A. K., Grayson, A. D., Fabri, B. M. \& Chalmers, J. A. C. Effect of risk-adjusted diabetes on mortality and morbidity after coronary artery bypass surgery. Ann. Thorac. Surg. 79, 1570-1576 (2005).

31. Carson, J. L. et al. Diabetes mellitus increases short-term mortality and morbidity in patients undergoing coronary artery bypass graft surgery. J. Am. Coll. Cardiol. 40, 418-423 (2002).

32. Liu, S. et al. Clinical determinants of diabetes progression in multiethnic Asians with type 2 diabetes-a 3-year prospective cohort study. Ann. Acad. Med. Singapore 48, 217-223 (2019).

33. Tabák, A. G., Herder, C., Rathmann, W., Brunner, E. J. \& Kivimäki, M. Prediabetes: A high-risk state for diabetes development. Lancet 379, 2279-2290 (2012).

34. Stratton, I. M. Association of glycaemia with macrovascular and microvascular complications of type 2 diabetes (UKPDS 35): Prospective observational study. BMJ 321, 405-412 (2000).

35. Tan, E. et al. Effect of multidisciplinary intensive targeted care in improving diabetes mellitus outcomes: A randomized controlled pilot study - the Integrated Diabetes Education, Awareness and Lifestyle modification in Singapore (IDEALS) Program. Trials 20, 549 (2019).

36. Karter, A. J. et al. Elevated rates of diabetes in Pacific Islanders and Asian subgroups: The Diabetes Study of Northern California (DISTANCE). Diabetes Care 36, 574-579 (2013).

37. Gujral, U. P., Narayan, K. M. V., Kandula, N. R., Liu, K. \& Kanaya, A. M. Incidence of diabetes and prediabetes and predictors of glycemic change among South Asians in the USA: The MASALA study. BMJ Open Diabetes Res. Care 8, 20 (2020).

38. Tan, K. H. X. et al. Diabetes mellitus prevalence is increasing in South Asians but is stable in Chinese living in Singapore and Mauritius. J. Diabetes 9, 855-864 (2017). 
39. Narayan, K. M. V. \& Kanaya, A. M. Why are South Asians prone to type 2 diabetes? A hypothesis based on underexplored pathways. Diabetologia 63, 1103-1109 (2020).

40. International Diabetes Federation. https://idf.org/our-network/regions-members/western-pacific/members/113-singapore.html. Accessed 08 Aug 2020.

41. Biesman-Simons, T. et al. A multicentre prospective observational study of the prevalence and glycaemic control of diabetes mellitus in adult non-cardiac elective surgical patients in hospitals in Western Cape Province, South Africa. South Afr. Med. J. 109, 801-806 (2019).

42. Abdelmalak, B. et al. The prevalence of undiagnosed diabetes in non-cardiac surgery patients, an observational study. Can. J. Anaesth. 57, 1058-1064 (2010).

43. Teo, W. W. et al. The neglected perioperative population of undiagnosed diabetics-a retrospective cohort study. BMC Surg. 20, $188(2020)$.

44. Ministry of Health, Singapore. National Population Health Survey 2016/17. https://www.moh.gov.sg/resources-statistics/reports/ national-population-health-survey-2016-17. Accessed 08 Aug 2020

45. Nathan, D. M., Turgeon, H. \& Regan, S. Relationship between glycated haemoglobin levels and mean glucose levels over time. Diabetologia 50, 2239-2244 (2007).

46. Wheeler, E. et al. Impact of common genetic determinants of Hemoglobin Alc on type 2 diabetes risk and diagnosis in ancestrally diverse populations: A transethnic genome-wide meta-analysis. PLoS Med. 14, e1002383 (2017).

47. Roberts, W. L. et al. Effects of hemoglobin C and S traits on glycohemoglobin measurements by eleven methods. Clin. Chem. 51, 776-778 (2005).

48. Gallagher, E. J., Le Roith, D. \& Bloomgarden, Z. Review of hemoglobin A1c in the management of diabetes. J. Diabetes 1, 9-17 (2009).

49. Ford, E. S., Cowie, C. C., Li, C., Handelsman, Y. \& Bloomgarden, Z. T. Iron-deficiency anemia, non-iron-deficiency anemia and HbAlc among adults in the US. J. Diabetes 3, 67-73 (2011).

50. Guo, W., Zhou, Q., Jia, Y. \& Xu, J. Increased levels of glycated hemoglobin A1c and iron deficiency anemia: A review. Med. Sci. Monit. 25, 8371-8378 (2019).

51. Meigs, J. B., Cupples, L. A. \& Wilson, P. W. Parental transmission of type 2 diabetes: The Framingham Offspring Study. Diabetes 49, 2201-2207 (2000).

52. Harrison, T. A. et al. Family history of diabetes as a potential public health tool. Am. J. Prev. Med. 24, 152-159 (2003).

53. InterAct Consortium et al. The link between family history and risk of type 2 diabetes is not explained by anthropometric, lifestyle or genetic risk factors: The EPIC-InterAct study. Diabetologia 56, 60-69 (2013).

54. Bucerius, J. et al. Impact of diabetes mellitus on cardiac surgery outcome. Thorac. Cardiovasc. Surg. 51, 11-16 (2003).

\section{Acknowledgements}

The authors would like to thank Ms Thin Thiri Naing, Ms Stephanie Man Chung Fook-Chong and Mr Brendan Zhi-Ying Chong for their assistance with the study.

\section{Author contributions}

W.Y.L. and H.R.A.- - conceived the study, analysed the results and contributed to the manuscript. I.K.L.S. and C.H.G.- collected data and contributed to the manuscript. L.M.T. and Y.K.- analysed the results and contributed to the manuscript.

\section{Funding}

This work was funded by the SingHealth-Duke NUS Anaesthesiology Academic Clinical Program Pilot Research Grant 2019 (ANAESPRG19/04). The funding sources have no role in the design of this study and the analysis and interpretation of the results. HRA is a recipient of SingHealth Duke-NUS Nurturing Clinician Scientists Scheme Award, project number 12/FY2017/P1/15-A29 and National Medical Research Council (NMRC), Singapore, Clinician Investigator Salary Support scheme 2018-2020.

\section{Competing interests}

The authors declare no competing interests.

\section{Additional information}

Correspondence and requests for materials should be addressed to L.M.T. or H.R.A.

Reprints and permissions information is available at www.nature.com/reprints.

Publisher's note Springer Nature remains neutral with regard to jurisdictional claims in published maps and institutional affiliations.

(c) (i) Open Access This article is licensed under a Creative Commons Attribution 4.0 International License, which permits use, sharing, adaptation, distribution and reproduction in any medium or format, as long as you give appropriate credit to the original author(s) and the source, provide a link to the Creative Commons licence, and indicate if changes were made. The images or other third party material in this article are included in the article's Creative Commons licence, unless indicated otherwise in a credit line to the material. If material is not included in the article's Creative Commons licence and your intended use is not permitted by statutory regulation or exceeds the permitted use, you will need to obtain permission directly from the copyright holder. To view a copy of this licence, visit http://creativecommons.org/licenses/by/4.0/.

(C) The Author(s) 2020 